\title{
Loss of pulmonary elastic recoil in workers formerly exposed to proteolytic enzyme (alcalase) in the detergent industry
}

\author{
A. W. MUSK and BRYAN GANDEVIA \\ University of New South Wales Department of Medicine, Prince Henry Hospital, \\ Sydney, Australia
}

\begin{abstract}
Musk, A. W., and Gandevia, B. (1976). British Journal of Industrial Medicine, 33, 158-165. Loss of pulmonary elastic recoil in workers formerly exposed to proteolytic enzyme (alcalase) in the detergent industry. Sixty-seven workers in the detergent industry whose exposure to proteolytic enzyme ceased in 1969 have been examined clinically and functionally. By comparison with 42 lightly and moderately exposed subjects, 13 heavily exposed subjects showed significant loss of pulmonary elastic recoil as evidenced by increased lung volumes and increased pulmonary compliance, but there were no differences in airways resistance or other parameters of lung function. No difference was found between the two groups in relation to symptoms on exposure, current exercise tolerance, skin reactivity to the proteolytic enzyme alcalase, trypsin inhibitor capacity, and other features. An increased clinical grade of breathlessness was associated with evidence of airways obstruction, but not of altered elastic recoil. Comparison of the data on lung mechanics with results obtained in 1970 suggests that partial recovery of pulmonary elastic recoil may have occurred in some cases. It is also suggested that diminished elastic recoil, in the absence of impairment of transfer factor at rest, may reflect altered physical properties of the lung fibre network without loss of effective surface area available for gas exchange.
\end{abstract}

A survey of 98 workers in the detergent industry in 1969 indicated the presence of asthmatic symptoms in $50 \%$ of the workforce during periods of exposure to the proteolytic enzyme alcalase derived from B. subtilis, but tests of ventilatory capacity and transfer factor in these employees showed no evidence of loss of lung function (Mitchell and Gandevia, 1971a). Subsequent bronchial challenge tests with doses less than those likely to be encountered in a day's work confirmed the occurrence of asthmatic symptoms in some subjects, with or without manifest skin reactivity, and also revealed a virtually asymptomatic pulmonary reaction characterized by diffuse fine râles and interpreted as occurring in small airways (Mitchell and Gandevia, 1971b). In 1970, detailed studies of lung mechanics in 37 subjects, selected on the basis of degree of exposure, demonstrated significant loss of pulmonary elastic recoil in the group classified as heavily exposed by comparison with those lightly exposed (Mitchell, 1976; Gandevia and Mitchell, 1973).

Alcalase has not been used in the detergent industry in Australia since 1969. Re-investigation of all available employees or ex-employees was undertaken three years later as part of an agreement made in 1969 between management and trade unions.

\section{Subjects and methods}

The present series comprises 67 subjects (60 men and seven women). Of the 98 workers studied in 1969, all of the 49 still employed at the factory agreed to re-investigation. Attempts were made to contact all past employees; of 26 who could be located, 20 replied and 18 consented to further studies. The inevitable selection is 
not epidemiologically ideal, but review of all the information available, including the results of the three previous studies, reveals no evidence of any bias in the subjects accepting re-investigation which might influence the interpretation of the present results.

Estimates made in 1969 of the severity of exposure were available for 64 subjects. These assessments, which took into account known place and type of work and the environmental enzyme levels measured after some initial improvement in dust control (Simson and Simpson, 1971), were as follows:

1. Heavily exposed: those subjects who had handled the pure commercial enzyme in its original finely divided dusty form, or who had worked in adjacent areas known to have had high environmental levels.

2. Moderately exposed: those subjects heavily exposed to the end product, in which the enzyme is diluted, usually at the packeting machines or in the reclaiming process.

3. Lightly exposed: those subjects lightly exposed only to the final product, working usually on the packeting machines or in the store.

Three subjects with little exposure and normal lung function have been excluded from most comparisons because data from the 1969 survey were not complete.

Answers to questions put in 1969 concerning respiratory symptoms (nasal symptoms, cough, sputum, wheeze, chest tightness, and shortness of breath) during or after exposure to enzymes (Mitchell and Gandevia, 1971a) were available for 52 subjects (46 men and six women) and were grouped as follows:

1. Symptoms on minimal exposure -13 men, 1 woman

2. Symptoms on moderate exposure -7 men, 2 women

3. Symptoms on heavy exposure only -10 men

4. No symptoms on heavy exposure-10 men, 2 women

5. No symptoms but no heavy exposure-6 men, 1 woman.

Employees were studied over a period of one week at the factory site in a portable laboratory unit designed for occupational surveys. Ex-employees were brought to the hospital and studied in the same laboratory during the next three months.

\section{Questionnaire}

All subjects answered a standard questionnaire on respiratory symptoms. Subjects were considered to have dyspnoea if they answered 'Yes' to the question 'Do you get short of breath on exertion more easily than others of your age?' None of the subjects answering in the affirmative to the question 'Have you ever had asthma?', had asthma at the time of the study. Allergic rhinitis was regarded as present when the answer 'Yes' was given to 'Do you get hay fever?' or 'Have you ever been told by your doctor that there were polyps in your nose?'

All participants were questioned concerning smoking habit. Non-smokers had never smoked cigarettes regularly, ex-smokers had ceased smoking more than three months before the study, and smokers were smoking cigarettes regularly within three months of the survey. No subject regularly smoked a pipe or cigars.

Physical examination

Auscultation of the lung bases was carried out and a requested cough was graded loose (productive) or dry
(Hall and Gandevia, 1971). Râles were considered to be present if discontinuous crackling sounds were heard, whether or not they were transient on repeated deep breaths; good agreement was found between two observers although the results are analysed only in terms of the findings of one (AWM).

\section{Skin tests}

As an index of atopic status, prick tests were carried out to common allergens of known potency consisting of grass pollens, house dust, Aspergillus, and cat and dog hair (Commonwealth Serum Laboratories). A score was given according to the total number of ' + 's obtained for the common allergens (alcalase excluded) using the following grading:

- no palpable wheal

+ palpable wheal less than $2 \mathrm{~mm}$ in diameter

++ palpable wheal between 2 and $4 \mathrm{~mm}$ in diameter

+++ palpable wheal greater than $4 \mathrm{~mm}$ in diameter.

Subjects were also classified as reactive on skin tests if they had a ++ or greater reaction to one or more of the common allergens and as non-reactive if no reaction of this size was obtained. Alcalase for prick testing was prepared by adding $0.5 \mathrm{mg}$ dry powdered enzyme supplied by Lever Bros. to $0.5 \mathrm{ml}$ water to produce a concentration of $1 \mathrm{mg} / \mathrm{ml}$ (Pepys et al., 1969).

\section{Respiratory function}

Ventilatory capacity Forced expiratory volume in one second $\left(\mathrm{FEV}_{1}\right)$ was measured with the subject seated using a 9-litre Collins spirometer. Values were corrected to BTPS.

Single breath carbon monoxide diffusing capacity (transfer factor) This was performed using the method of Ogilvie et al. (1957), as modified by Cotes (1968). A Resparameter Mark IV (P K Morgan) was used with a washout volume of $700 \mathrm{ml}$, alveolar sample of $600 \mathrm{ml}$, and a breath-holding time of $10 \mathrm{~s}$. Gas analysis was by gas chromatography. Inspired gas consisted of $5 \%$ neon, $0.4 \%$ carbon monoxide, $21 \%$ oxygen, and the balance nitrogen. Alveolar volume, transfer factor ( $\left.D_{L C O}\right)$, and diffusion constant $\left(\mathrm{K}_{\mathrm{Co}}\right)$ were calculated (Cotes, 1968).

Lung volumes and flow-volume curves Inspiratory vital capacity (VC) was that measured at the time of estimation of diffusing capacity (corrected to BTPS). The functional residual capacity (FRC), inspiratory capacity and flowvolume curves were measured in a volume displacement body plethysmograph (Emerson) as described by Mead (1960). Mouth pressure was measured with a Statham differential strain gauge (Model PM 131 TC) and box volume with a Krogh spirometer corrected by a box pressure signal for phase and amplitude distortion. Flow-volume curves were recorded on a storage oscilloscope screen using a Fleisch pneumotachograph No. 4 connected to a Statham transducer PM 97. Flow was later measured at $50 \%$ of total lung capacity ( $\dot{\mathrm{V}} \max$ $50 \%$ TLC).

Pulmonary compliance Oesophageal pressure measurements were made by the technique of Milic-Emili et al. (1964a and b). Volume change was measured in the body plethysmograph. In accordance with the technique of 
Finucane and Colebatch (1969), five separate staticdeflation volume-transpulmonary pressure curves were performed on each subject. Each curve was recorded directly on to the storage oscilloscope screen, photographed and subsequently measured, the points from the five separate deflations being transferred on to a single volume-pressure diagram. Pulmonary compliance $\left(C_{L}\right.$ stat) was taken at the slope of the curve over the litre above functional residual capacity. The lung volume at transpulmonary pressure of $10 \mathrm{~cm} \mathrm{H}_{2} \mathrm{O}\left(\mathrm{V}_{\mathrm{L}} 10 \mathrm{~cm} \mathrm{H}_{2} \mathrm{O}\right)$ was read from the curve. Transpulmonary pressure at TLC and transpulmonary pressure (relaxed) at TLC were taken as the means of the three highest values for these measurements. Static tidal compliance $\left(C_{L}\right.$ stat tidal) was measured by interruption during tidal breathing, the volume-pressure points being similarly recorded and analysed.

Pulmonary resistance $\left(\mathbf{R}_{\mathrm{L}}\right)$ This was measured during tidal breathing using a method of electrical subtraction (Mead and Whittenberger, 1953).

Of the 64 subjects (excluding the three with incomplete 1969 data) in whom measurements of ventilatory and diffusing capacities were made, four subjects would not enter the body plethysmograph, and in eight the oesophageal balloon was not passed because the subject refused or the attempt failed. In one subject the recordings of oesophageal pressure were considered technically unsatisfactory, For comparison of results between exposure groups, lung volume results were therefore available in 60 subjects and lung mechanics in 51 .
Trypsin-inhibitor capacity

This was estimated using benzoyl-arginine-p-nitroanili as substrate (Erlanger, Kokowsky, and Cohen, 1961) on subjects as a group, with control sera from patients $w$ : known deficiency.

\section{Chest radiographs}

Standard posterior-anterior and lateral radiographs 62 subjects revealed no material abnormalities, and su minor changes as were noted (for example, promine bronchial walls) were unrelated to severity of exposure.

\section{Results}

No differences in the results of lung function te: were found between the light and moderate exposu groups in this or in the previous follow-up surv (Mitchell, 1976; Gandevia and Mitchell, 1973), as on both occasions the mean values for those ligh1 or moderately exposed fell within the normal rang established in this laboratory. These two grou have therefore been combined for comparison wi the heavily exposed group.

Table 1 sets out the general characteristics of bo exposure groups.

\section{Clinical features}

A history of asthma or vasomotor rhinitis occurr with similar frequency in both exposure groul

TABLE 1

General Characteristics

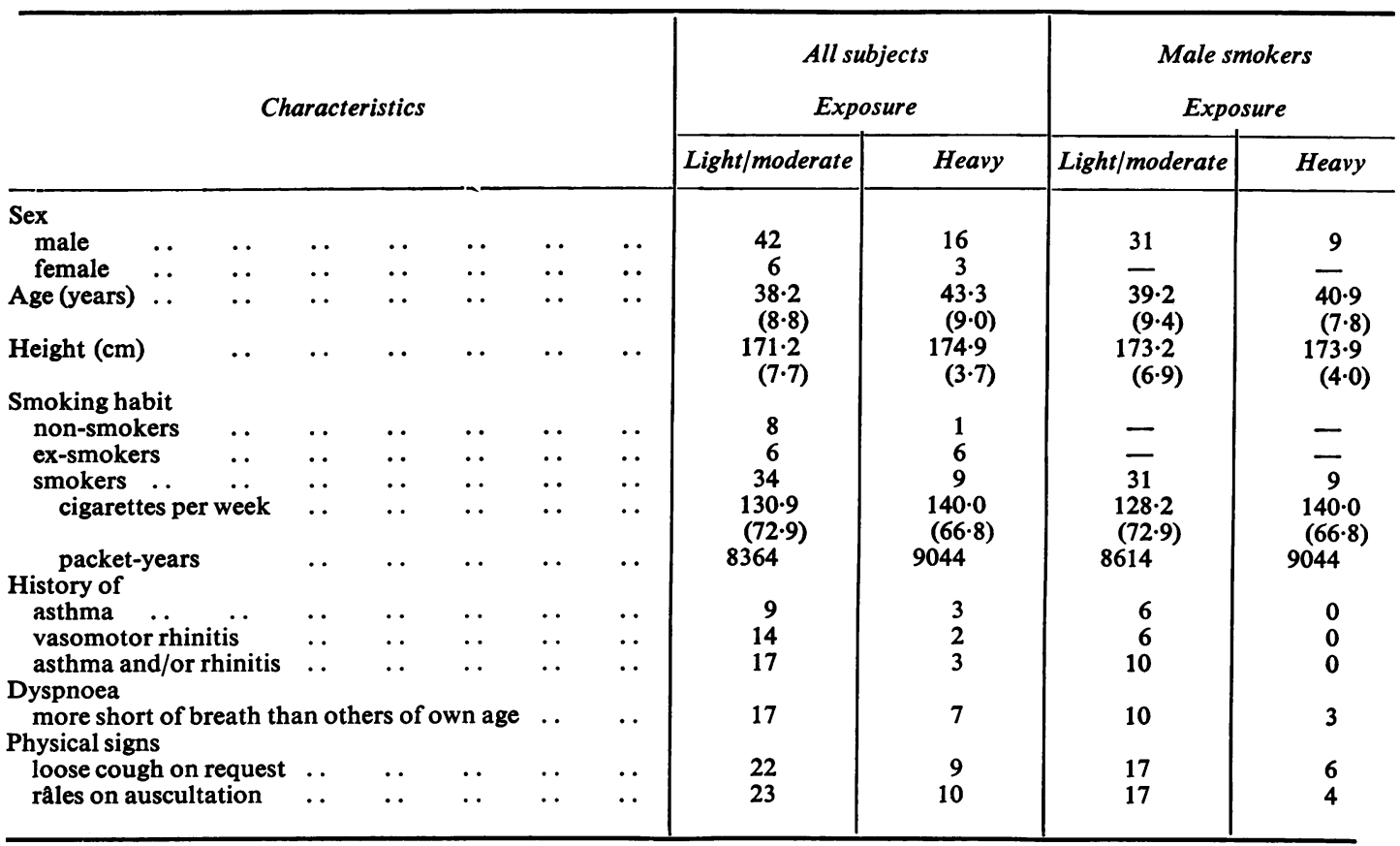

Standard deviation of mean values in parentheses. Other figures indicate number of subjects 
The prevalence of dyspnoea, loose cough, and râles was also similar.

\section{Skin reactivity}

The number of subjects with positive skin tests to alcalase and other inhalants was not significantly different in the two exposure groups (Table 2). In the absence of further exposure, apparent changes in skin reactivity had occurred in either direction in $8 \%$ of 46 subjects tested in 1969 and 1972.

\section{Symptoms on exposure}

No differences were found between the subjects with or without a recorded history of symptoms on occupational exposure in 1969, either in terms of other clinical features or in relation to the results of any of the lung function tests.

\section{Current dyspnoea}

A history of cough and sputum $(P<0.05)$, 'asthma' $(P<0.05)$ and the presence of a loose cough on request $(P<0.01)$ were significantly more frequent in the 26 admitting to current dyspnoea than in the 41 subjects with normal exercise tolerance. Lung function results for the men complaining of dyspnoea were significantly different from the men with a presumably normal exercise tolerance in indices of airways obstruction, namely $\mathrm{FEV}_{1}, \mathrm{FEV}_{\mathbf{1}} / \mathrm{VC}(\%)$, $\dot{V} \max 50 \%$ TLC, and $R_{L}$ (Table 3 , in which the results have been standardized for age and height). No significant differences were demonstrable between these two symptom groups in relation to any of the indices of pulmonary elastic recoil.

\section{Lung function tests}

The results of lung function tests are shown in Table 4. Significantly higher values in the heavily exposed group were found for TLC, $C_{L}$ stat, $C_{L}$ stat tidal, and $V_{\mathrm{L}} 10 \mathrm{~cm} \mathrm{H}_{2} \mathrm{O}$. Transpulmonary pressures at TLC were less in the heavily exposed group but the differences were not significant. The Figure shows the mean curves for the two groups.
$\mathrm{K}_{\mathrm{Co}}$ was lower, but not significantly so, in the heavily exposed group, but this reflects a greater alveolar volume in this group. Because of the different mean ages and heights between the exposure groups (Table 1) all results were standardized to the average age and height of the series on the basis of a linear regression derived from all the data for each test (Snedcor and Cochran, 1967). Comparison then revealed that the difference in TLC between the groups was no longer statistically significant but the other differences remained.

When non-smokers, ex-smokers, and women are excluded comparison of standardized or unstandardized data between exposure groups with similar smoking habits confirms the changes found for the unmodified groups. Total lung capacity again emerged as significantly greater in the heavily exposed group.

In both comparisons, $\mathrm{FEV}_{1}, \mathrm{R}_{\mathrm{L}}$, and $\dot{\mathrm{V}} \max 50 \%$ TLC are similar in the two exposure groups.

\section{Comparison of 1969 and 1972 results}

For those subjects who were included in the functional studies in 1969 and 1972 there has been an overall change in results (Table 5). Although the mean changes are of greater magnitude in the heavily exposed, they are significant only in the lightly and moderately exposed for $C_{L}$ stat and lung volume at transpulmonary pressure $10 \mathrm{~cm} \mathrm{H}_{2} \mathrm{O}$. The trend in both groups is consistent with an increase in elastic recoil, in that there is a decrease in TLC and in lung volume at a transpulmonary pressure of $10 \mathrm{~cm} \mathrm{H}_{2} \mathrm{O}$, a decrease in $\mathrm{C}_{L}$ stat, and an increase in transpulmonary pressure (relaxed) at TLC. Analysis of results for individuals reflects a similar internal consistency. Of the 21 subjects on whom all these indices were available for both 1969 and 1972, nine (five lightly or moderately exposed and four heavily exposed) showed the changes of increased recoil and one (heavily exposed) showed changes of decreased elastic recoil. The remaining 11 showed inconsistent but small changes.

TABLE 2

SKIN REACTIVITY

\begin{tabular}{|c|c|c|c|c|c|}
\hline \multicolumn{2}{|l|}{ Reactivity } & \multicolumn{2}{|c|}{$\begin{array}{c}\text { All subjects } \\
\text { Exposure }\end{array}$} & \multicolumn{2}{|c|}{$\begin{array}{c}\text { Male smokers } \\
\text { Exposure }\end{array}$} \\
\hline & & Light/moderate & Heavy & Light/moderate & Heavy \\
\hline 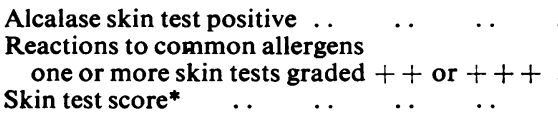 & $\begin{array}{ll}\cdots & \cdots \\
\cdots & \cdots \\
\cdots & \cdots\end{array}$ & $\begin{array}{l}25 \\
10 \\
1 \cdot 25 \\
(1 \cdot 87)\end{array}$ & $\begin{array}{l}13 \\
5 \\
0 \cdot 88 \\
(1 \cdot 41)\end{array}$ & $\begin{array}{l}19 \\
7 \\
0 \cdot 78 \\
(1 \cdot 72)\end{array}$ & $\begin{array}{l}8 \\
2 \\
1 \cdot 48 \\
(1 \cdot 88)\end{array}$ \\
\hline
\end{tabular}

*Mean score with standard deviation in parentheses 
TABLE 3

Current Dyspnoea*

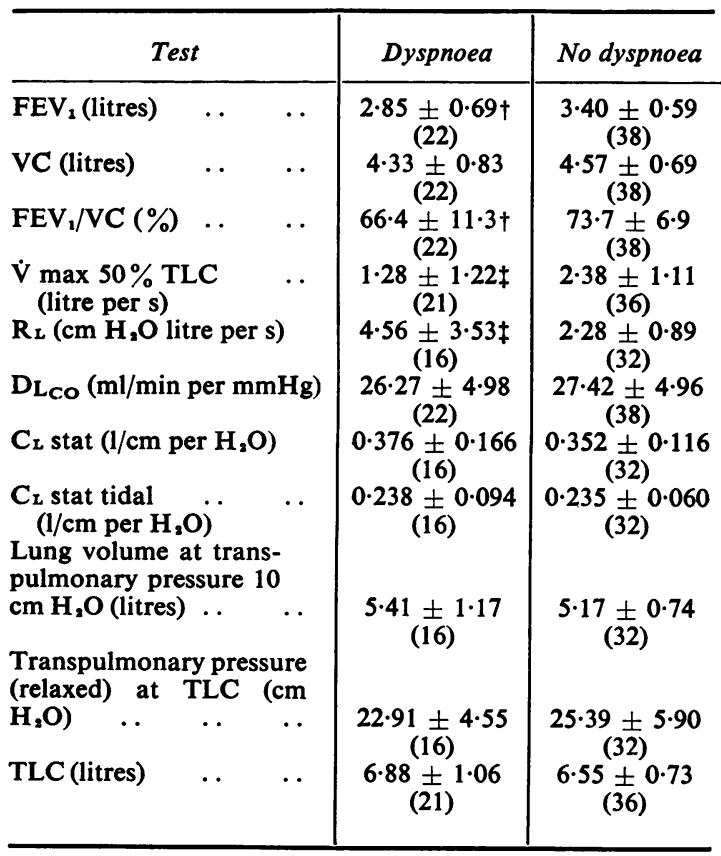

* Male subjects only; age and height corrected data Statistical significance of difference between groups: $\dagger=P<0.005 \ddagger=P<0.001$

Trypsin-inhibitor capacity In three subjects (two lightly or moderately exposed and one heavily exposed) trypsin-inhibitor capacity was markedly reduced but not absent. A further 10 subjects (six lightly or moderately exposed and four heavily exposed) showed an intermediate reduction in activity. As a group the subjects with decreased antitrypsin activity could not be distinguished from those with normal activity either clinically or by pulmonary function tests; one individual with intermediate antitrypsin activity showed changes of decreased pulmonary elastic recoil, but none of those with markedly reduced activity.

\section{Discussion}

Compared with a group of lightly and moderately exposed workers, subjects formerly heavily exposed to alcalase show loss of pulmonary elastic recoil but no differences in airway function or transfer factor. The present findings in all available employees therefore confirm results previously obtained in a series of subjects selected specifically on the basis of exposure (Gandevia and Mitchell, 1973). Neither study reveals any indication that factors other than severity of exposure (such as exposure, skin sen- sitivity, respiratory symptoms and signs, or trypsininhibitory capacity) are related to this altered pattern of functional behaviour.

The heavily exposed workers could not be differentiated from lightly or moderately exposed workers on the basis of current symptoms of dyspnoea on exertion, physical signs of a productive cough or râles on auscultation of the chest, skin reactivity to alcalase or common respiratory allergens, or respiratory symptoms during the period of exposure some years ago. Tests of ventilatory capacity, diffusing capacity, and pulmonary resistance also show no differences, indicating the failure of these tests to reflect an alteration in elastic recoil (Knudson et al., 1973). Weill, Wadell, and Ziskind (1971) also found no differences between heavily and lightly exposed subjects in these aspects of lung function. The failure of symptoms on exposure to be correlated with loss of pulmonary elastic recoil is not unexpected, partly because symptomatic reactions are likely to reflect reactions in mediumsized bronchi, and partly because virtually asymptomatic acute reactions, occurring probably in small airways, have been observed in the course of provocation tests (Mitchell and Gandevia, 1971b)* and during occupational exposure.

Loss of elastic recoil may be secondary to bronchial obstruction (Finucane and Colebatch, 1969; Colebatch, Finucane, and Smith, 1973; Gelb et al., 1973) but this is an unlikely explanation for the present results. Subjects with loss of elastic recoil as a result of bronchial disease have had severe and persisting airway obstruction (Finucane and Colebatch, 1969) indicated by a reduction in $\mathrm{FEV}_{1}, \mathrm{VC}$, and airway conductance. None of our subjects had airway obstruction of a severity comparable with that found in some asthmatic subjects (Colebatch et al., 1973) nor had they suffered clinical syndromes of comparable severity in the past, except perhaps in a few instances for short periods before they stopped using enzymes in 1969. In any case, bronchial obstruction associated with increased TLC and decreased transpulmonary pressure at TLC tends to decrease rather than increase lung compliance as a result of early exclusion of some lung units (Finucane and Colebatch, 1969).

The volume-pressure characteristics of the lungs in the group of workers heavily exposed to alcalase deviate from the group moderately or lightly exposed in the same direction as the abnormality found in animals with papain-induced experimental emphysema (Pushpakom et al., 1970; Caldwell, 1972) or in human subjects with structural emphysema (Finucane and Colebatch, 1969; Colebatch et al., 1973). In experimental emphysema the steady-state

*We should like to stress that we do not advocate challenge tests with active enzyme preparations 
TABLE 4

Results of Respiratory Function Tests

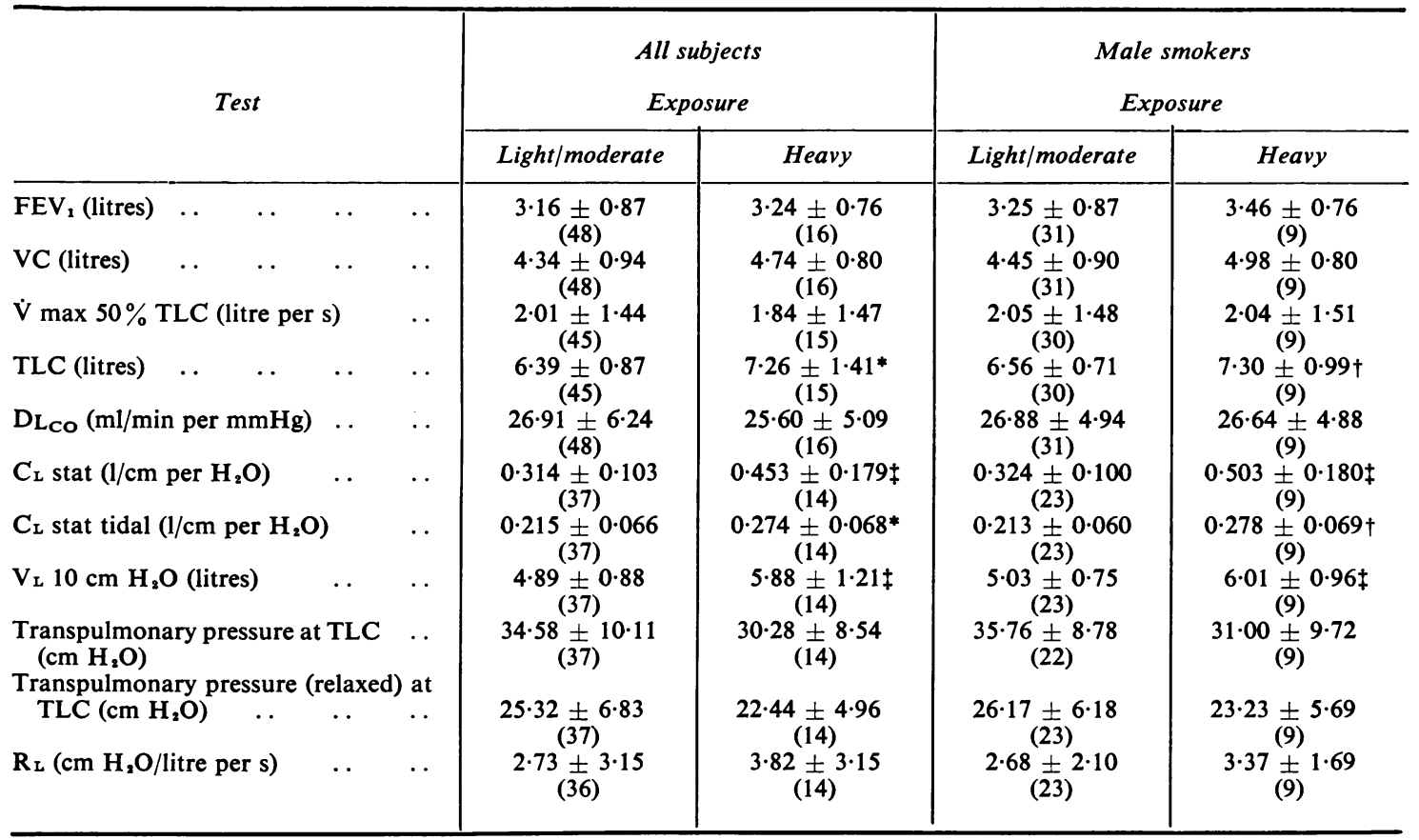

Mean values \pm 1 standard deviation. Unstandardized results. Figures in parentheses indicate number of subjects.

Statistical significance between groups: ${ }^{*} \mathrm{P}<0.01+\mathrm{P}<0.05 \ddagger \mathrm{P}<0.005$

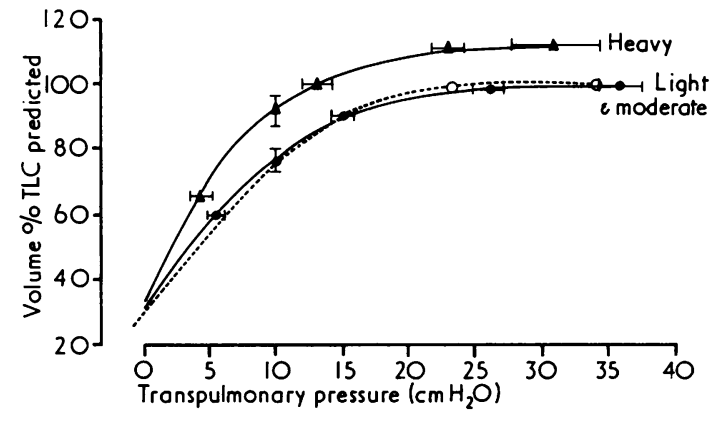

FIGURE. Mean static deflation volume-pressure curves from total lung capcity to residual volume in nine subjects heavily exposed to alcalase and 31 lightly and moderately exposed (men only, non-smokers and ex-smokers excluded). Interrupted curve indicates normal curve for 10 subjects (Colebatch et al., 1973). Horizontal lines show the standard error of the mean for each transpulmonary pressure measurement and vertical line the standard error of the mean for lung volume at transpulmonary pressure of $10 \mathrm{~cm} \mathrm{H}_{2} \mathrm{O}$.
TABLE 5

COMPARISON OF 1970 AND 1972 Results

\begin{tabular}{|c|c|c|c|c|}
\hline \multicolumn{3}{|c|}{ Test } & \multirow{2}{*}{$\begin{array}{c}\begin{array}{c}\text { Light/moderate } \\
\text { exposure }\end{array} \\
-0.14 \pm 0.52 \\
\text { (22) }\end{array}$} & \multirow{2}{*}{$\begin{array}{c}\begin{array}{c}\text { Heavy } \\
\text { exposure }\end{array} \\
-0.29 \pm 0.69\end{array}$} \\
\hline FEV $_{1}$ (litres) & .. & . & & \\
\hline VंC (litres) & . & . & $-0.40 \pm 0.62$ & $-0.55 \pm 0.48$ \\
\hline \multicolumn{3}{|c|}{$\begin{array}{l}\text { Static deflation compliance } \\
\quad\left(1 / \mathrm{cm} \mathrm{H}_{2} \mathrm{O}\right)\end{array}$} & $\begin{array}{c}-0.079 \pm \\
0.114 \dagger \\
(17)\end{array}$ & $\begin{array}{c}-0.158 \pm \\
0.273 \\
(10)\end{array}$ \\
\hline \multirow{2}{*}{\multicolumn{3}{|c|}{$\begin{array}{l}\text { Transpulmonary pressure } \\
\text { (relaxed) at TLC } \\
\quad \text { (cm } \mathrm{H}_{2} \mathrm{O} \text { ) } \\
\text { Lung volume at transpul- } \\
\text { monary pressure } 10 \mathrm{~cm}\end{array}$}} & $\begin{array}{c}+3 \cdot 74 \pm 5 \cdot 16 \\
(15)\end{array}$ & $\begin{array}{c}3 \cdot 07 \pm 4.28 \\
(9)\end{array}$ \\
\hline & & & & \\
\hline $\mathrm{H}_{2} \mathrm{O}$ (litres) & 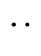 & . & $\begin{array}{c}-0.55 \pm 0.90 \dagger \\
(17)\end{array}$ & $-\underset{(10)}{-0.80 \pm 0.92}$ \\
\hline TLC (litres) & $\cdots$ & .. & $-0.32 \pm 0.80$ & $-0.48 \pm 1.24$ \\
\hline
\end{tabular}

*Mean differences between 1969 and 1972 results \pm 1 standard deviation.

Numbers in parentheses are number of subjects tested

tStatistical significance of change between 1970 and 1972 in direction of increased elastic recoil (single-tailed Student's $t$ test) $\mathrm{P}<0.05$ 
carbon monoxide diffusing capacity is decreased .(Pushpakom et al., 1970) and in human subjects with emphysema the single breath carbon monoxide diffusing capacity is diminished (Ogilvie et al., 1957; Gelb et al., 1973; Bates, 1958; Bedell and Ostiguy, 1967). In this investigation the transfer factor of the lung was the same in the lightly or moderately exposed and in the heavily exposed, but the differences in elastic recoil measurements between the two groups are not of the same magnitude as those found between clinical emphysema and normality (Finucane and Colebatch, 1969). It is thus unlikely that in our cases there is widespread destruction of alveolar septa with loss of pulmonary capillaries, but the fibre network may still have been affected; focal emphysema may be produced experimentally by alcalase (Goldring et al., 1972). This may serve as a possible explanation for our finding, if it is accepted that measurement of transfer factor at rest may not be sufficiently sensitive to reflect relatively small changes in effective surface area; a current project is directed towards the study of this problem.

Gandevia and Mitchell (1973) found evidence in two subjects heavily exposed to alcalase of progressive loss of elastic recoil between 1969 and 1970, after exposure had ceased. A third subject showed no change after a period of months. Except in one subject, the present investigation does not provide evidence for further loss of pulmonary elastic recoil after enzyme exposure had ceased. Systematic variations between the 1969 and 1972 results may have occurred from the use of the nitrogen washout technique for the estimation of FRC in 1969, and the use of different equipment and personnel. These factors will not account for the observed increase in elastic recoil because internally consistent changes were found in two independent measurements (volume and pressure), and because the magnitude of the change would require inconceivably large systematic errors in calibration, beyond the recorded day-to-day calibration variations. Furthermore, the plethysmographic method of deriving TLC is likely to give a result larger than the nitrogen washout method (Tierney and Nadel, 1962), the reverse of the observed change between the two studies. The evidence is therefore against a progressive loss of elastic recoil in the two and a half years since last exposure to proteolytic enzymes, and more suggestive of its restoration, although individual cases may deteriorate. No clinical or functional evidence to suggest interstitial disease has emerged from this study or from the initial survey (Gandevia and Mitchell, 1973).

The observed loss of elastic recoil in the heavily exposed group cannot be responsible for limitation of exercise tolerance, and the symptom of undue breathlessness on exertion was in fact described with equal frequency in both exposure groups. On the other hand, this symptom was significantly associated with clinical and functional evidence of disordered airway function. In the present context, the clinical and medico-legal importance of diminished elastic recoil may lie not so much in the possible development of advanced (clinical) emphysema as in its facilitation of the effect of a bronchoconstrictor agent. In cases of asthma, initiated by occupational exposure to alcalase, confirmed by skin and bronchial sensitivity tests, and recurring after cessation of exposure, this mechanism may be contributory.

We are indebted to management, employees, and trade union leaders for their co-operation in this investigation. Professor H. J. H. Colebatch and Dr G. B. Field have given invaluable assistance in methodology, interpretation of results, and preparation of this report. Grants in support of the unit's occupational research have been provided by the Workers' Compensation (Dust Diseases) Board of New South Wales, the Joint Coal Board of New South Wales, the Australian Tobacco Research Foundation, the Asthma Foundation of New South Wales, and by industry. Our thanks are also due to Dr V. Kalyanasundaram, Mr P. Owen, and Mrs R. Tester for their assistance in conducting the survey, and to Professor R. J. Bartholomew, Division of Clinical Chemistry, for estimating the trypsin-inhibitor capacity of serum samples. We are grateful to Dr Charles Mitchell, who initiated the studies of lung mechanics in this occupational group, for information concerning the previous investigations in these workers.

\section{References}

Bates, D. V. (1958). The measurement of the pulmonary diffusing capacity in the presence of lung disease. Journal of Clinical Investigation, 37, 591-605.

Bedell, G. N. and Ostiguy, G. L. (1967). Transfer factor for carbon monoxide in patients with airways obstruction. Clinical Science, 32, 239-248.

Caldwell, E. J. (1972). The physiologic and anatomic effects of papain on the rabbit lung. In Pulmonary Emphysema and Proteolysis, edited by C. Mittman, pp. 487-494. Academic Press, New York.

Colebatch, H. J. H., Finucane, K. E., and Smith, M. M. (1973). Pulmonary conductance and elastic recoil relationship in asthma and emphysema. Journal of Applied Physiology, 34, 143-153.

Cotes, J. E. (1968). Lung Function, pp. 234 and 245, 2nd ed. Blackwell, Oxford.

Erlanger, B. F., Kokowsky, N., and Cohen, W. (1961). The preparation and properties of two new chromogenic substrates of trypsin. Archives of Biochemistry and Biophysics, 95, 271-278.

Finucane, K. E. and Colebatch, H. J. H. (1969). Elastic behavior of the lung in patients with airway obstruction. Journal of Applied Physiology, 26, 330-338.

Gandevia, B. and Mitchell, C. A. (1973). Loss of pulmonary elastic recoil in workers heavily exposed to proteolytic enzymes in the detergent industry. In Proceedings of the IVth International Pneumoconiosis Conference (ILO), Bucharest, pp. 515-521. Apimondia, 
Bucharest, Romania. (Summary, correspondence. Medical Journal of Australia (1971), 1, 1032-1033.)

Gelb, A. F., Gold, W. M., Wright, R. R., Bruch, H. R., and Nadel, J. A. (1973). Physiologic diagnosis of subclinical emphysema. American Review of Respiratory Diseases, 107, 50-63.

Goldring, I. P., Park, S. S., Greenberg, L., and Ratner, I. M. (1972). Sequential anatomic changes in lungs exposed to papain and other proteolytic enzymes. In Pulmonary Emphysema and Proteolysis, edited by C. Mittman, pp. 389-397. Academic Press, New York.

Hall, G. J. L. and Gandevia, B. (1971). Relationship of the loose cough sign to daily sputum volume. British Journal of Preventive and Social Medicine, 25, 109-113.

Knudson, R. J., Mead, J., Goldman, M. D., Schwaber, J. R., and Wohl, M. E. (1973). The failure of indirect indices of lung elastic recoil. American Review of Respiratory Diseases, 107, 70-82.

Mead, J. (1960). Volume displacement body plethysmograph for respiratory measurements in human subjects. Journal of Applied Physiology, 15, 736-740.

- and Whittenberger, J. L. (1953). Physical properties of human lungs measured during spontaneous respiration. Journal of Applied Physiology, 5, 779-796.

Milic-Emili, J., Mead, J., and Turner, J. M. (1964a). Topography of esophageal pressure as a function of posture in man. Journal of Applied Physiology, 19, 212-216.

,,--- , and Glauser, E. M. (1964b). Improved technique for estimating pleural pressure from esophageal balloons. Journal of Applied Physiology, 19, 207-211.

Mitchell, C. A. (1976). Decreased pulmonary elastic recoil in workers heavily exposed to proteolytic enzymes used in the detergent industry. (In preparation).

- and Gandevia, B. (1971a). Respiratory symptoms and skin reactivity in workers exposed to proteolytic enzymes in the detergent industry. American Review of Respiratory Diseases, 104, 1-12.

- and - (1971b). Acute bronchiolitis following provocative inhalation of 'alcalase'-a proteolytic enzyme used in the detergent industry. Medical Journal of Australia, 1, 1363-1367.

Ogilvie, C. M., Forster, R. E., Blakemore, W. S., and Morton, J. W. (1957). A standardized breath holding technique for the clinical measurement of the diffusing capacity of the lung for carbon monoxide. Journal of Clinical Investigation, 36, 1-17.

Pepys, J., Hargreave, F. E., Longbottom, J. L., and Faux, J. (1969). Allergic reactions of the lungs to enzymes of Bacillus subtilis. Lancet, 1, 1181-1184.

Pushpakom, R., Hogg, J. C., Woolcock, A. J., Angus, A. E., Macklem, P. T., and Thurlbeck, W. M. (1970). Experimental papain-induced emphysema in dogs. American Review of Respiratory Diseases, 102, 778-789.

Simson, R. E. and Simpson, G. R. (1971). The dangers of proteolytic enzymes to workers. Medical Journal of Australia, 1, 1242-1243.

Snedcor, G. W. and Cochran, W. G. (1967). Statistical Methods, 6th ed., ch. 6. Iowa State University Press, Iowa.

Tierney, D. F. and Nadel, J. A. (1962). Concurrent measurements of functional residual capacity by three methods. Journal of Applied Physiology, 17, 871-873.

Weill, H., Wadell, L. C., and Ziskind, M. (1971). A study of workers exposed to detergent enzymes. Journal of the American Medical Association, 217, 425-433.

Received for publication 7 January 1975 Accepted for publication 17 June 1975 